\title{
Negative Consequences of Substance Use in European University Students: Results from Project SNIPE
}

\author{
John McAlaney ${ }^{a}$ Robert C. Dempseyb,c Stefanie M. Helmer ${ }^{d}$ Guido Van Hal \\ Bridgette M. Bewick ${ }^{f}$ Yildiz Akvardarg Francisco Guillén-Grimah, i, j, k \\ Ol'ga Orosovál Ondrej Kalinal Christiane Stock ${ }^{d}$ Hajo Zeeb ${ }^{m, n}$
}

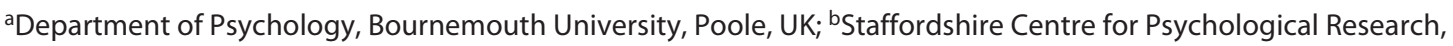
School of Life Sciences \& Education, Staffordshire University, Stoke-on-Trent, UK; 'Department of Psychology,

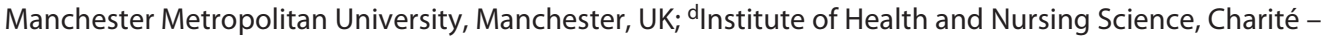
Universitätsmedizin Berlin, Corporate member of Freie Universität Berlin, Humboldt-Universität zu Berlin, and Berlin

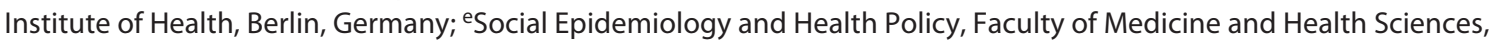

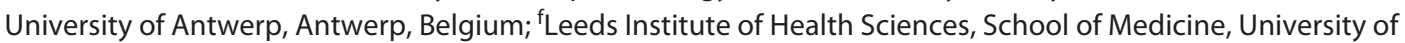
Leeds, Leeds, UK; ${ }^{9}$ Department of Psychiatry, School of Medicine, Marmara University, Istanbul, Turkey; ${ }^{\text {hDepartment }}$ of Health Sciences, Public University of Navarra, Pamplona, Pamplona, Spain; 'IdiSNA, Navarra Institute for Health

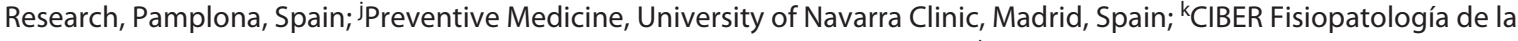
Obesidad y Nutrición (CIBERObn), Instituto de Salud Carlos III, Madrid, Spain; 'Department of Educational Psychology \& Health Psychology, Faculty of Arts, Pavol Jozef Safarik University in Kosice, Kosice, Slovakia; mDepartment of Prevention

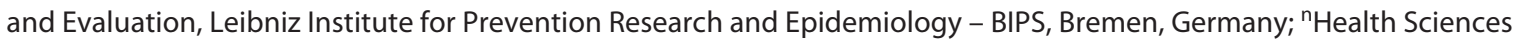
Bremen, University of Bremen, Bremen, Germany

\section{Keywords}

Substance use · Consequences · Students · University · Health

\begin{abstract}
Background: University students are a risk group for heavy substance use and the experience of various potentially severe negative substance use consequences which may impact on their health, social, and academic functioning. Whilst the experience of negative consequences of substance use is well understood in North American student samples, there is little data on these experiences in European students. In order to develop effective harm preven-
\end{abstract}

karger@karger.com www.karger.com/ear

Karger $\stackrel{\text { ' }}{5}$

GOPEN ACCESS
(C) 2020 The Author(s)

Published by S. Karger AG, Basel

This article is licensed under the Creative Commons AttributionNonCommercial-NoDerivatives 4.0 International License (CC BY NC-ND) (http://www.karger.com/Services/OpenAccessLicense) Usage and distribution for commercial purposes as well as any distribution of modified material requires written permission. tion and reduction interventions for students' substance use, there needs to be an understanding of the types of consequences experienced in European student samples. $\mathbf{O b}$ jectives: The aim of the study was to investigate the prevalence and predictors of the experience of negative substance use-related consequences amongst university students in 7 European countries. Methods: University students $(n=4,482)$ in Belgium, Denmark, Germany, the Slovak Republic, Spain, Turkey, and the UK completed an online survey of their substance use behaviours and the experience of associated negative consequences. Results: European students reported that experiencing a hangover or illness, missing class, being short of money, and experiencing memory loss were the most commonly experienced nega- 
tive consequences of substance use. Not living with other students and using alcohol, cannabis, sedatives, and cocaine were also associated with higher odds of experiencing these negative consequences. Conclusions: In contrast to North American data, European university students tended to experience consequences that are associated with lower level health risks rather than more severe consequences (e.g., drink-driving and physical injury). Harm prevention and reduction interventions for students should be targeted towards those consequences that are most salient to the target group to ensure feedback is relevant and potentially more effective in changing students' substance use behaviours.

(C) 2020 The Author(s)

Published by S. Karger AG, Basel

\section{Introduction}

The transition to university is associated with peaks of substance use. Students aged between 20 and 22 years use substances at a greater rate than their nonstudent peers, indicating that a combination of this age and student status is a risk factor for increased substance use $[1,2]$. For many individuals, attending university or college coincides with the transition into adulthood and development of new social networks, and may represent the first period in their lives where they live independently without immediate parental supervision [3]. The use of substances tends to decrease over the course of university studies, with later years of study being associated with lower use and further decreases seen post-completion of studies [2].

The use of licit and illicit substances by students can be associated with a range of negative academic, social, and health-related consequences. Common negative consequences experienced by students include driving a car whilst under the influence of alcohol and other substances (lifetime estimates range from around 30 to $50 \%$ of students sampled) $[2,4,5]$; being physically injured due to alcohol consumption [2] (estimated rates vary for alcohol, although rates of injury to self and/or others associated with the use of other substances, e.g., cannabis, appear to be lower at less than 5\% [4]); hangovers, nausea, and next-day feelings of tiredness and sluggishness (between 30 and 70\%) [4, 6, 7]; risky sexual behaviours (3-20\%) $[4,6,8]$; and getting into fights or arguments with others (2-28\%) [4,6-8]. There are, however, notable differences amongst studies on how such consequences are defined and measured, such as "risky sexual behaviour" potentially being inclusive of promiscuity, unprotected sex, and/or unwanted or unintended sexual activity $[4,6,7]$. Students' substance use may also have severe long-term harmful effects on their physical health, including negative effects on the immune system [2], to risks of early death by overdose or substance use-related traffic accidents [5]. Heavy substance use by students may have negative consequences beyond the effects on the individual, such as negative consequences for healthcare systems; for example, there is evidence that individuals with heavier and riskier alcohol use are more likely to use more expensive healthcare services (e.g., emergency departments) and require longer hospital stays than light alcohol users [9]. It is acknowledged, however, that students may experience a number of less severe negative consequences of substance use which may not pose immediate health risks, such as short-term memory loss or engaging in behaviours that they later regret when not intoxicated $[2,8]$. In addition, negative effects of substance use on academic performance can be common, including missing teaching sessions, poor performance in assessments, less time spent studying, and a general disengagement from one's studies $[2,3,10]$. A common issue with the literature on the negative consequences associated with students' substance use is the dominance of data on US and North American students' experiences, particularly the consequences associated with alcohol use [3]. There is a lack of understanding of the consequences experienced outside of American student samples and in relation to substance use more broadly.

Obtaining reliable and comparable estimates of the extent of these negative consequences can be a difficult due to differences in how consequences are recorded in empirical studies and in official crime and hospital reports, the lack of college/university student identifiers in such reports, and the potential underreporting of some severe consequences of substance use such as sexual assaults [11]. Also, few data exist on the types of negative consequences of substance use experienced by European university students. Available data tend to focus on pan-European consequences of severe substance usage (e.g., health risks associated with opioid addiction and needle use) at the general population level [12] or in younger adolescent age groups [13]. Such data may not appropriately capture the use of substances by university students or their associated consequences. Substance use by students may vary from regular patterns of consumption to more occasional usage depending on the type of substances used and the point of the academic year the use is
McAlaney et al. 
Table 1. Sample characteristics

\begin{tabular}{|c|c|c|c|c|c|c|c|}
\hline & \multicolumn{7}{|l|}{ Country } \\
\hline & $\begin{array}{l}\text { Slovak Republic } \\
(n=1,931)\end{array}$ & $\begin{array}{l}\text { Denmark } \\
(n=461)\end{array}$ & $\begin{array}{l}\text { Germany } \\
(n=503)\end{array}$ & $\begin{array}{l}\text { Belgium } \\
(n=424)\end{array}$ & $\begin{array}{l}\text { Spain } \\
(n=184)\end{array}$ & $\begin{array}{l}\text { Turkey } \\
(n=855)\end{array}$ & $\begin{array}{l}\text { UK } \\
(n=107)\end{array}$ \\
\hline \multicolumn{8}{|l|}{ Sex, \% } \\
\hline Female & 79 & 78 & 59 & 79 & 72 & 53 & 69 \\
\hline Male & 21 & 22 & 41 & 21 & 28 & 47 & 31 \\
\hline $21-25$ & 67 & 60 & 57 & 39 & 42 & 54 & 30 \\
\hline $26-30$ & 2 & 17 & 24 & 4 & 9 & 4 & 12 \\
\hline $31+$ & 1 & 11 & 8 & 4 & 10 & 1 & 19 \\
\hline $\begin{array}{l}\text { Residence (\% living with } \\
\text { other students) }\end{array}$ & 52 & 12 & 36 & 22 & 22 & 26 & 51 \\
\hline
\end{tabular}

$n$ indicates number of participants who have given information on sex.

assessed (e.g., during assessment periods where usage may change). There is a clear need for data on European students' experiences of the consequences of substance use.

There are also notable differences between the US and North American university systems and their on-campus substance use cultures (particularly for alcohol) compared to those in Europe; for example, higher rates of alcohol use are typically found amongst European students, but heavier usage on North American campuses is often associated with specific subgroups, such as the sorority/ fraternity and the competitive sports programmes unique to North American university systems [3, 14]. Given the cultural and structural differences between North American college systems and European universities, data on the types of negative consequences of substance use experienced by European students are needed to ensure an adequate understanding of European students' experiences. This understanding will inform the development of effective behaviour change interventions for university students that target the most salient, relevant, and widely experienced negative consequences of substance use [15]. Given the lack of cross-European studies of the prevalence of negative consequences of substance use, our study investigated the prevalence of and the predictors of the experience of negative consequences associated with substance use based on a secondary analysis of data collected during the Social Norms Intervention for the Prevention of Polydrug usE (SNIPE) study from a large-scale sample of European university students from 7 countries [16].

Negative Consequences of Substance Use in European Students

\section{Materials and Methods}

\section{Participants}

All registered students at each of the participating institutions in the SNIPE project were eligible to take part in this study. The SNIPE project was a feasibility trial of an online personalised social norms feedback system funded by the European Commission. The final sample included 4,482 students (see Table 1 for a breakdown of the sample characteristics by country).

\section{Materials}

Respondents were asked to report their frequency of use of alcohol, tobacco, cannabis, non-prescribed stimulants (e.g., Rital$\left.\mathrm{in}^{\mathrm{TM}}\right)$, synthetic cannabis, cocaine, ecstasy, other amphetamines, non-prescribed sedatives, hallucinogens, and inhalants. The survey also included items listing common negative consequences of substance use (featuring item wording based on existing measures, e.g., the ASSIST [17]): "How often in the last 2 months has the following happened to you because of using alcohol or any other substances?" For both frequency of substance use and frequency of experiencing consequences, the following response options were used: "never in my life," "have used but not in the last 2 months," "once in the last 2 months," "twice in the last 2 months," "once every week in the last 2 months," "twice every week in the last 2 months," " 3 times every week in the last 2 months," " 4 times every week in the last 2 months," and "every day or nearly every day in the last 2 months." In addition, respondents were asked to report their age, sex, living situation (with other students or not), and country.

\section{Procedure}

An online survey was used to collect data from students at universities in Belgium, Denmark, Germany, Spain, Turkey, the Slovak Republic, and the UK. The link to this survey was disseminated in a variety of ways, including via email lists, flyers, and social media posts (for further details, see [16]). Institutional ethical approval was given by all participating institutions prior to data collection. 
Table 2. Consequences of substance use experienced by students in the last 2 months and in their lifetime

\begin{tabular}{lll}
\hline Consequence as a result of using alcohol or any other substance & In the last 2 months, \% & In lifetime, \% \\
\hline Felt hungover or ill & 35 & 69 \\
Missed class & 20 & 51 \\
Were short of money & 19 & 44 \\
Experienced memory loss & 15 & 44 \\
Performed poorly on a test & 72 & 34 \\
Had unprotected sex & 6 & 27 \\
Been injured & 4 & 35 \\
Rode as a passenger in a vehicle with a driver under the influence & 3 & 27 \\
Had unintended or unwanted sexual contact & 3 & 17 \\
Had to receive emergency medical treatment & 2 & 11 \\
Got into a fight or other confrontation & 2 & 17 \\
Damaged property & 2 & 15 \\
Drove a vehicle whilst under the influence & 2 & 9 \\
Got into trouble with police or university security & & 9
\end{tabular}

\section{Data Analysis}

The percentage of respondents who reported having experienced each of the consequences in the last 2 months or at all in their lifetime was calculated (Table 2). Binary logistic regression was then conducted on the 6 most commonly reported consequences of substance use, as listed in Table 2. The predictors used in each of these 6 logistic regressions were age, sex, living situation (with other students or not with other students), frequency of use of individual substances (i.e., those substances listed in Table 2), and country. Year of study, typical and maximum number of alcoholic drinks on a drinking day, and frequency of drunkenness were controlled for. The outcome variable in each regression model was dichotomized based on the median split. For the 2 most frequently reported consequences, being hungover/ill and missing a class, the outcome variable was dichotomized as having happened in the last 2 months or not having happened in the last 2 months. For the remaining four consequences of being short of money, experiencing memory loss, performing poorly on a test, and having unprotected sex, the outcome variable was dichotomized as ever versus never (lifetime prevalence).

\section{Results}

Table 2 displays the percentage of students who reported experiencing a negative consequence of substance use in the last 2 months or in their lifetime. Fifty-three percent of the sample reported experiencing 4 or more consequences in their lifetime, with $12 \%$ reporting experiencing 4 or more consequences in the last 2 months. The most frequently reported consequences of substance use in the last 2 months were feeling hungover/ill, missing class, money difficulties, memory loss, and poor academic test performance. These consequences were also amongst the most frequently reported in our sample's lifetime, with physical injury (35\%), being a passenger in a car with a drunk driver (27\%), and unintended or unwanted sexual contact (17\%) being the more frequently reported lifetime consequences.

The outcomes of the binary logistic regression analyses are shown in Table 3. All the regression models were statistically significant. For brevity, we have not reported the frequency of use of the substances assessed here; this information can be found in other publications associated with the SNIPE project [18-23].

The logistic regression analyses indicated that male students had greater odds of reporting feeling hungover/ ill (odds ratio [OR]: 1.3, confidence interval [CI]: 1.051.62) but lower odds of having performed poorly on a test (OR: 0.75, CI: 0.64-0.88). Overall, there were no notable gender differences in the consequences reported by students when frequency of substance use was adjusted for. Age did not appear to be a strong predictor of the consequences analysed in the regression models; however, this may be reflective of the fact that the sample mostly comprised younger university students (aged 25 years and below). Not living with other students appeared to be associated with an increased risk of experiencing all selected consequences, even with the other variables being controlled for. There were some differences in the consequences reported by respondents of the different countries in comparison to the reference category (the Slovak Republic; note that this country was chosen as the reference category based on the sample size and that such choices are arbitrary for logistic regression models). Students from the UK (OR: 3.32, CI: 1.49-7.39) and Turkey (OR: 5.35, CI: 2.31-12.36) had greater odds of reporting having felt hungover or ill in the last 2 months. Students 


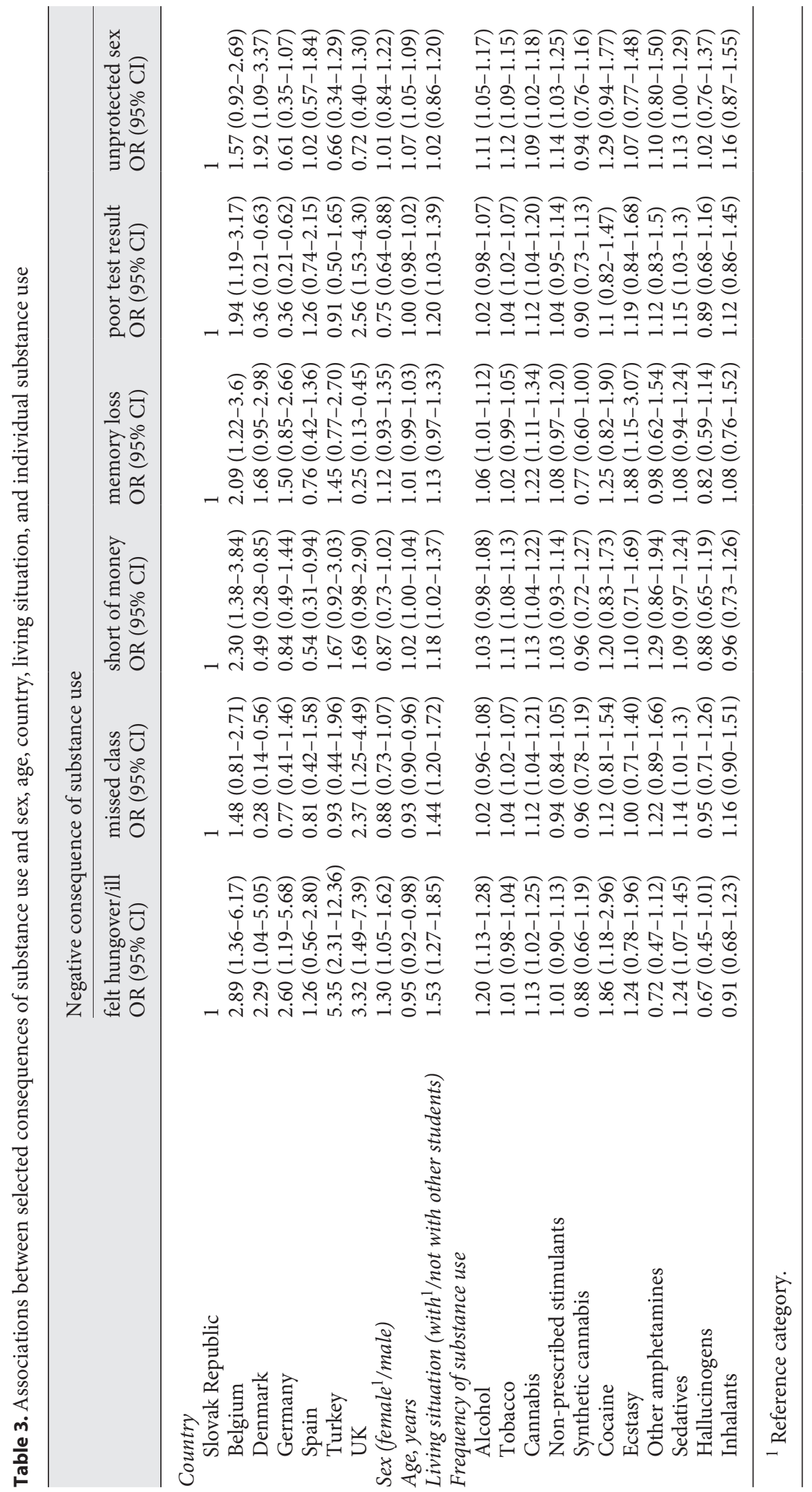


from Germany (OR: 0.36, CI: 0.21-0.63) and Denmark (OR: 0.36, CI: 0.21-0.62) had lower odds of reporting that they had performed poorly on a test in their lifetime as a result of substance use.

\section{Discussion/Conclusion}

There is a lack of understanding of the negative consequences of substance use experienced by European university students. To date, most of the research has focused on the experiences of negative consequences of substance use amongst students in the North American university system. This is problematic for understanding the experience of European university students due to differences in higher education systems and substance use cultures amongst European students compared to North American students [14]. To address this gap, the current study investigated the prevalence and predictors of the experience of several key negative consequences of substance use by a large number of students sampled from 7 European countries.

The most frequently reported negative consequence in this European student sample was the experience of feeling hungover or ill after substance use, followed by missing teaching sessions, being short of money, having memory problems, and poor performance on academic tests. This order of consequences was the same for recent (last 2 months) and lifetime experiences. A number of consequences were recently experienced by less than $10 \%$ of the sample (albeit with higher lifetime rates), including physical injury, getting into fights or confrontations, having unintended or unwanted sexual contact, requiring emergency treatment, damaging property, and getting into trouble with the police or university/campus security. Of particular note in the current study is the comparatively low reported frequency of students who drove whilst under the influence of substances or who rode as passengers with an intoxicated driver, across both the recent ( 2 months) and lifetime time frames. These figures (driving under the influence or being a passenger with a drug/drunk driver) are particularly low compared to those reported in North American studies [25]. Also, in contrast to many North American studies, the 5 most common negative consequences of substance use in this study are arguably those that pose a low immediate risk to the participants' health, highlighting a key difference between American and European university students' experiences of substance use consequences. However, whilst the reported $2 \%$ figure of students driving under the influence in the last 2 months may seem low, there are approximately 20 million students in tertiary education across Europe
[24] and $2 \%$ of this population could represent a significant number of drink/drug-driving incidents with potentially significant consequences.

In terms of the predictors associated with the experience of negative consequences of substance use, we found that not living with other students was associated with higher odds of experiencing the 6 most common negative consequences of substance use measured in this study. In contrast to the existing work in the USA and North America, where close proximity to other students and living in halls of residence appear to be risk factors for heavier substance use and the experience of more consequences of use (e.g., Refs. [2] and [3]), European students in our study appeared to be at higher risk for experiencing consequences when they are not in close proximity to their peers. For European students, there may be a protective effect of living with other students which may prevent the experience of longer term severe consequences associated with substance use (e.g., one's peers may act to intervene when they witness a fellow student experiencing one of the consequences reported here). One possibility is that European students who experience more of these negative consequences tend to live with nonstudents who engage in heavy patterns of substance use, such as same-age nonstudent peers or possibly family members. Indeed, there is some evidence (albeit US-based) to suggest that student users of more illicit substances, including cannabis, may be more influenced by the perceived norms and behaviours of their close friends and parents, rather than those of the typical student at their institution [25]. It may be that European students experiencing more of these negative consequences tend to live in environments with non-students who are permissive and engage in heavier substance usage themselves.

It was also notable that there was little effect of age and participants' sex in the logistic regression models, although there could be potential interactive effects of participant's sex and living with same-sex students in terms of predicting the experience of these negative consequences of substance use (e.g., male students living with other males could be at higher risk). We were unable to test this assertion as we only measured the participants' broad residential status (e.g., whether they lived with other students or not) and not the composition of these residences in terms of sex ratios, which may be an avenue for further investigations. Finally, we noted that a greater frequency of use of several key substances (namely, alcohol, cannabis, sedatives, and cocaine) was associated with higher odds of the most commonly reported negative consequences of substance use as analysed in the regression models. Whilst our data do not allow for a finer grained analysis of how the use of these substances
Eur Addict Res 2021;27:75-82 DOI: $10.1159 / 000507438$
McAlaney et al. 
is associated with these specific consequences, as the consequence items were written without reference to any specific substance and our data are cross-sectional in nature, it may be that the concomitant use of these substances (i.e., "polysubstance" use) remains a risk factor for the experience of more negative consequences and requires targeting in future harm prevention strategies.

There are some clear implications for future interventions focusing on European students' substance use. Given that our sample reported common negative consequences of substance use which generally pose low immediate risks to their overall well-being (e.g., hangovers, missing classes, and money problems), intervention feedback which focus on the more extreme and life-threatening consequences of substance use may be perceived to be of low relevance to European students. Indeed, health education approaches for substance use which focus on the more unlikely consequences of substance use have been criticised for their effectiveness [26], and students may correctly identify that such extreme negative outcomes may be unlikely to happen to them. Rather, intervention feedback should target those consequences that are most concerning and have most impact on the target students; for example, missing a class was the second most reported consequence of substance use in the current study, which may be a salient consequence to highlight in harm prevention/reduction messages. Further research in this area will allow for the development of prevention and harm reduction strategies for substance misuse consequences that are most relevant to student populations being targeted.

There are some strengths and limitations to consider with this study; primarily, this was a cross-sectional study that relied on self-reporting of substance behaviours and is subject to the limitations inherent to study designs of this type. The survey wording queried whether respondents had experienced any of the consequences as a result of any substance use. Given that several substances can be consumed at the same time, possibly for different reasons, it is difficult to disentangle the individual consequences brought about by using individual substances. Whilst the experience of hangovers and illness following substance use was the most common recent and lifetime consequence of substance use, this could itself be a contributory factor for some of the other consequences reported by respondents, such as missing classes or performing poorly on tests. There were also some unequal sample sizes between the seven countries sampled in this study, which may limit the generalizability of some of these findings; however, this is the first study, to our knowledge, which has investigated the prevalence and predictors of the neg-

Negative Consequences of Substance Use in European Students ative consequences of substance use in a large-scale European student sample. Finally, it should be noted that this study focused exclusively on negative consequences associated with substance use and that many students may experience various positive substance-related consequences (e.g., increased sociability and pleasure [6]).

In conclusion, the types of negative consequences of substance use experienced by university students appear to differ between European and American samples, with the primary difference being that European students tend to report experiencing more low-level and less immediately health-threatening consequences of substance use than their North American counterparts. The current study highlights the need for intervention efforts to focus on the relevant and most commonly experienced consequences for the target group, rather than attempting to generalize the experience of North American students to students studying in other countries with different educational systems, cultures, and substance use legislation. Whilst the current study provides novel details on the type of negative consequences of substance use commonly experienced by European university students, there have been calls for research to better focus on the subjective experience of these consequences. Future work should consider that substance use-related consequences may not be experienced as negative by individual students [6] or that students are necessarily motivated to avoid such consequences [15], issues which should be factored into the design of future targeted intervention approaches that aim at reducing the incidence of such negative consequences of students' substance use.

\section{Statement of Ethics}

Institutional ethical approval was obtained from the respective research ethical review boards at all of the sites sampled as part of the SNIPE project. Participants provided their informed consent online prior to completing the baseline survey of the SNIPE project.

\section{Disclosure Statement}

C.S. received funding from TrygFonden (Danish Safety Foundation) for 2 research projects which are unrelated to the present article. B.M.B., as keynote speaker/expert advisor, has received reimbursement of travel expenses and/or time from the Society for the Study of Addiction, Anheuser-Busch, Noctis, the International Centre for Alcohol Policies, and the International Alliance for Responsible Drinking. B.M.B. has been a recipient of research grants provided by the European Research Advisory Board (ERAB) and by the International Alliance for Responsible Drinking. This funding is not connected to the work presented in this article. The remaining authors have no conflicts of interest to declare. 


\section{Funding Sources}

The SNIPE project was supported by a grant from the European Commission Directorate of Justice (LS/2009-2010/DPIP/ AG) and was registered on the German Clinical Trials Register (DRKS00004375). The funder had no input into the preparation of data or the manuscript.

\section{Author Contributions}

J.M. conducted the analyses and led the initial writing of the manuscript, with R.D. who led the revision of the manuscript following peer review. All coauthors contributed to the design of the study, data collection, and writing of the manuscript, and approved the final version of the manuscript submitted to the journal.

\section{References}

1 Bennett TH. Differences in the age-drug use curve among students and non-students in the UK. Drug Alcohol Rev. 2014;33(3):280-6.

2 Ham LS, Hope DA. College students and problematic drinking: a review of the literature. Clin Psychol Rev. 2003 Oct;23(5):71959.

3 Skidmore CR, Kaufman EA, Crowell SE. Substance use among college students. Child Adolesc Psychiatr Clin N Am. 2016;25(4):73553.

4 Pearson MR, Liese BS, Dvorak RD. College student marijuana involvement: perceptions, use, and consequences across 11 college campuses. Addict Behav. 2017 Mar;66:83-9.

5 Hingson R, Zha W, Smyth D. Magnitude and trends in heavy episodic drinking, alcoholimpaired driving, and alcohol-related mortality and overdose hospitalizations among emerging adults of college ages 18-24 in the United States, 1998-2014. J Stud Alcohol Drugs. 2017;78(4):540-8.

6 Park CL, Grant C Determinants of positive and negative consequences of alcohol consumption in college students: alcohol use, gender, and psychological characteristics. Addict Behav. 2004 Feb;30(4):755-65.

7 Ayala EE, Roseman D, Winseman JS, Mason HRC. Prevalence, perceptions, and consequences of substance use in medical students. Med Educ Online. 2017;22(1):1392824.

8 Davoren MP, Shiely F, Byrne M, Perry IJ. Hazardous alcohol consumption among university students in Ireland: a cross-sectional study. BMJ Open. 2015;5(1):e006045.

9 Miquel L, Manthey J, Rehm J, Vela E, Bustins M, Segura L, et al. Risky alcohol use: the impact on health service use. Eur Addict Res. 2018;24(5):234-4.

10 Arria AM, Caldeira KM, Bugbee BA, Vincent $\mathrm{KB}, \mathrm{O}$ 'Grady KE. The academic consequences of marijuana use during college. Psychol Addict Behav. 2015;29(3):564-75.

11 White A, Hingson R. The burden of alcohol use. Alcohol Res. 2014;35(2):201-18.
12 European Monitoring Centre for Drugs and Drug Addiction (EMCDDA). European drug report. Luxembourg: Publications Office of the European Union; 2019.

13 European School Survey Project on Alcohol and Other Drugs(ESPAD) Group. ESPAD report 2015: results from the European school survey project on alcohol and other drugs. Luxembourg. 2016.

14 Wicki M, Kuntsche E, Gmel G. Drinking at European universities? A review of students' alcohol use. Addict Behav. 2010;35(11):91324.

15 Mallett KA, Varvil-Weld L, Borsari B, Read JP, Neighbors C, White HR. An update of research examining college student alcohol-related consequences: new perspectives and implications for interventions. Alcohol Clin Exp Res. 2013;37(5):709-16.

16 Pischke CR, Zeeb H, van Hal G, Vriesacker B, McAlaney J, Bewick BM, et al. A feasibility trial to examine the social norms approach for the prevention and reduction of licit and illicit drug use in European University and college students. BMC Public Health, 2012; 12.882 .

17 Humeniuk R, Ali R, Babor TF, Farrell M, Formigoni ML, Jittiwutikarn J, et al. Validation of the alcohol, smoking and substance involvement screening test (ASSIST). Addiction. 2008;103(6):1039-47.

18 McAlaney J, Helmer SM, Stock C, Vriesacker B, van Hal G, Dempsey RC, et al. Personal and perceived peer use of and attitudes toward alcohol among university and college students in seven EU countries: project SNIPE. J Stud Alcohol Drugs. 2015;76(3):430-8.

19 Helmer SM, Mikolajczyk RT, McAlaney J, Vriesacker B, van Hal G, Akvardar Y, et al. Illicit substance use among university students from seven European countries: a comparison of personal and perceived peer use and attitudes towards illicit substance use. Prev Med. 2014;67:204-9.
20 Dempsey RC, McAlaney J, Helmer S, Pischke C, Akvardar Y, Bewick BM, et al. Normative perceptions of cannabis use amongst European University students: associations between perceived peer use and peer attitudes with personal use and attitudes. J Stud Alcohol Drugs. 2016;77(5):740-8.

21 Lehne G, Zeeb H, Pischke CR, Mikolajczyk R, Bewick BM, Mcalaney J, et al. Personal and perceived peer use and attitudes towards use of non-prescribed prescription sedatives and sleeping pills among university students in seven European countries. Addict Behav. 2018;87:17-23.

22 Pischke CR, Helmer SM, McAlaney J, Bewick BM, Vriesacker B, Van Hal G, et al. Normative misperceptions of tobacco use among university students in seven European countries: baseline findings of the 'Social Norms Intervention for the prevention of polydrug use' study. Addict Behav. 2015;51:158-64.

23 Helmer SM, Pischke CR, Van Hal G, Vriesacker B, Dempsey RC, Akvardar Y, et al. Personal and perceived peer use and attitudes towards the use of nonmedical prescription stimulants to improve academic performance among university students in seven European countries. Drug Alcohol Depend. 2016;168: $128-34$.

24 Eurostats. Tertiary education statistics [Internet]. 2018 [cited 2019 Aug 8]. Available from: https: //ec.europa.eu/eurostat/statistics-explained/index.php/Tertiary_education_statistics.

25 Napper LE, Kenney SR, Hummer JF, Fiorot S, LaBrie JW. Longitudinal relationships among perceived injunctive and descriptive norms and marijuana use. J Stud Alcohol Drugs. 2016;77(3):457-63.

26 Dempsey RC, McAlaney J, Bewick BM. A critical appraisal of the social norms approach as an interventional strategy for health-related behavior and attitude change. Front Psychol. 2018;9:2180. 